\title{
Efectos de Internet y las redes sociales en los corresponsales de guerra españoles
}

\section{The Internet and social networks' effects on Spanish war correspondents}

\author{
Eva Lavín de las Heras \\ Profesora de la Facultad de Comunicación \\ (Universidad Camilo José Cela) \\ Max Römer Pieretti \\ Director del Grado de Comunicación Audiovisual \\ (Universidad Camilo José Cela)
}

Fecha de recepción: 11 de febrero de 2015

Fecha de revisión: 20 de junio de 2015

Para citar este artículo: Lavín de las Heras, E. y Römer Pieretti, M. (2015):

Efectos de Internet y las redes sociales en los corresponsales de guerra españoles, Icono 14, volumen (13), pp. 192-213. doi: 10.7195/ri14.v13i2.783 


\section{Resumen}

La aparición de Internet y las redes sociales han provocado cambios en el paradigma informativo, en la actualidad la información ya no fluye de forma unidireccional, dando lugar a nuevos actores, los llamados periodistas ciudadanos. Pero también, ha obligado a los periodistas profesionales a utilizar estas nuevas herramientas para acercarse al usuario. Son muchos los estudios sobre estos efectos, pero pocos, los que los relacionan con el trabajo de los corresponsales de guerra españoles. Por ello, este artículo pretendemos investigar a través del método cualitativo, con la realización de catorce entrevistas en profundidad, cómo ha afectado a la cobertura de conflictos y en concreto a su trabajo, la aparición de estos nuevos medios.

\section{Palabras clave}

Comunicación - Periodismo - Corresponsales de guerra - Internet - Redes sociales Twitter

\section{Abstract}

The emergence of the Internet and social networks has change the news model. Nowadays, information no longer flows unidirectionally, leading to new players called citizen journalists. But it has also forced the professional journalists to use these new tools to approach the user. There are many studies on these effects, but few of them relate to the work of the Spanish war correspondents. Therefore, this article investigates through qualitative method with the completion of fourteen interviews and shows how it has affected the coverage of conflicts and in particular its work, the emergence of these new media.

\section{Key Words}

Communication - Journalism - War correspondent - Internet - Social networks 


\section{Introducción}

La aparición de Internet y las redes sociales han provocado un cambio en el periodismo de cobertura de conflictos, pero no es la primera vez que se enfrenta el periodismo a ello, ya con la creación del telégrafo, la prensa se convirtió en un medio de comunicación de masas, sufriendo uno de sus mayores cambios a lo largo de su historia. Las informaciones de los periódicos aumentaron su radio de acción además de ganar en credibilidad e inmediatez al acelerarse la transmisión. Las noticias aumentaron no sólo en número sino también en extensión, calidad y variedad en el contenido. Aparecieron los temas sensacionalistas y se empezó a jerarquizar la información al no poder publicar todos los telegramas recibidos en un día. Todo esto obligó a renovar el estilo periodístico que pasó de ser retórico y grandilocuente a ser conciso y claro. El corresponsal de guerra, acostumbrado a mandar sus largas crónicas, se tuvo que adaptar a la llegada de este nuevo medio que por su alto coste le obligaba a escribir crónicas más breves, dando lugar a la praxis de las 5W del periodismo -¿Quién?, ¿Quée, ¿Cuándo?, ¿Dónde? y ¿Por qué? (Braojos Garrido, García González, De Pablo Contreras, Paz Rebollo \& Scuzle Schneider, 1999).

Durante la guerra de Secesión norteamericana los periódicos demandaban información de "última hora", por lo que evidenció la importancia de la valía de los reporteros ya que de ellos dependía adelantarse al rival y dar la primicia sobre lo que estaba pasando. Los corresponsales tenían que pagar en efectivo antes de cada transmisión $\mathrm{y}$, ante la inestabilidad de las líneas telegráficas, se vieron obligados a hacer un breve resumen al principio de cada comunicación. Este sumario se acabaría instaurando en el periodismo norteamericano, así como otra innovación que acercó al lector al hecho noticioso, la inclusión de entrevistas a los protagonistas (Knightley, 2000).

El uso del telégrafo, la nueva tecnología de información y comunicación del siglo XIX, hizo que corresponsales carismáticos y seguidos por los lectores como William Russell, no supieran adaptarse a estos métodos que exigían más concentración y celeridad a la hora de transmitir. Acostumbrado a mandar sus crónicas por correo o mensajero, podía dedicarle un enfoque literario con una mayor extensión,

DOI: ri14.v13i2.783 | ISSN: 1697-8293 | Año 2015 Volumen 13 № 2 | ICONO14 
pero ahora se encontraba con un estilo antagónico que le pedía concreción e inmediatez (Knightley, 2000).

Avanzado el tiempo, ya después de las grandes guerras, la instantaneidad en la información, primero con los satélites de telecomunicación y después con la aparición de Internet, obligó a reorganizar el trabajo de los periodistas y por tanto la estructura de las salas de redacción de los medios de comunicación, transformando radicalmente la industria informativa. Estos medios informativos y los muchos cambios tecnológicos sucesivos en los últimos 50 años, provocaron una redefinición de las relaciones entre las empresas informativas, los periodistas y sus destinatarios dando lugar al llamado "periodismo digital", así como para el lector que también varió las formas de obtención de información de los mismos. Las noticias, entonces, rápidamente, la información vive en un estado de constante actualización y hay una relación interactiva entre el periodista y el receptor, imposible con los otros medios precedentes (Pavlik, 2005).

Pero la aparición de Internet, los blogs y las redes sociales también han dado lugar a un nuevo fenómeno vaticinado por autores como Bowman y Willis (2003) o Gillmor (2004), el llamado, periodismo ciudadano. Éste cambiaría el paradigma informativo permitiendo a cualquiera con un teléfono móvil con cámara y conexión a Internet, ser generador de noticias. La creación de redes sociales como Twitter, ha permitido que la comunicación entre millones de personas sea posible en cuestión de segundos, acceso al que sólo tenían derecho los medios de comunicación. En la actualidad, la información ya no fluye de forma unidireccional, por ello algunos medios ya se han adelantado y han creado herramientas para fomentar la participación ciudadana (Lavín, 2014), siendo ya habitual ver en las televisiones o en la prensa, imágenes de conflictos que no han sido captadas por corresponsales 0 periodistas profesionales.

Pero también los medios les han pedido a los corresponsales que sean activos y utilicen estas herramientas para aproximarse a los usuarios, como en el golpe de Estado en Egipto de julio de 2013 en la que los propios corresponsales subían a Twitter fotos para mostrar lo que estaba pasando en directo. 
En la actualidad todos estos fenómenos están provocando cambios en el periodismo, siendo pocos los estudios que se centran en la figura del corresponsal de guerra, quizás uno de los más afectados. Es evidente que los avances tecnológicos han mejorado la comunicación y la transmisión de la información, pero también han traído consigo otras consecuencias no tan beneficiosas. Por ello, nos proponemos estudiar los efectos de Internet y las redes sociales en el trabajo de los corresponsales de guerra españoles, analizando los factores que han incidido en su quehacer y sus posibles consecuencias.

\section{Método}

El estudio que se presenta proviene de un análisis de contenido a 15 entrevistas en profundidad a corresponsales de guerra españoles. La discriminación que se hizo para determinar estos 15 perfiles se logró considerando como parámetros los siguientes: que hayan trabajado en un medio de comunicación que tuviera cobertura sobre todo el territorio español, que hubiesen cubierto por lo menos cinco conflictos y que hayan ejercido por lo menos durante 8 años su profesión.

Como resultado de esa criba, se generó la tabla que se presenta a continuación:

\begin{tabular}{|c|c|c|}
\hline Nombre & Tipo de medio & Nombre del medio \\
\hline Alfonso Armada & Prensa & ABC \\
\hline Ángeles Espinosa & Prensa & El País \\
\hline Enric González & Prensa & El País \\
\hline Guillermo Altares & Prensa & El País \\
\hline Javier Espinosa & Prensa & El Mundo \\
\hline Alfonso Rojo & Prensa & La Vanguardia \\
\hline Tomás Alcoverro & Prensa & Poder \\
\hline Mónica G. Prieto & Prensa digital & Periodismo Humano \\
\hline Fran Sevilla & Radio & TVE \\
\hline Vicente Romero & Televisión & Antena 3 \\
\hline Javier Mellado & Televisión & El Heraldo de Aragón \\
\hline Gervasio Sánchez & Fotoperiodista & \\
\hline
\end{tabular}




\begin{tabular}{|c|c|c|}
\hline Nombre & Tipo de medio & Nombre del medio \\
\hline Antonio Pampliega & Freelance & $\begin{array}{c}\text { La Sexta noticias, Público y } \\
\text { agencia France Press }\end{array}$ \\
\hline Alfonso Bauluz & Agencia de noticias & Agencia EFE \\
\hline
\end{tabular}

Fuente: Elaboración propia

Las entrevistas en profundidad se realizaron con un guion que se centraba fundamentalmente en cuestiones sobre el impacto de las nuevas tecnologías y los nuevos medios (Internet y las redes sociales) en su profesión, para posteriormente analizar el contenido desde los postulados de la Teoría Fundamentada desarrollada por Strauss y Corbin (2002). Esta metodología cualitativa permitió explorar el campo del periodismo de guerra, del que hay pocos análisis y por tanto, información insuficiente para elaborar una hipótesis consistente. Además pudimos centrarlo así, en el campo que nos interesaba que era su relación las nuevas herramientas permitiéndonos desgranar cómo ha afectado estas a su trabajo.

\section{Desarrollo}

\subsection{Efectos de Internet las redes sociales en el corresponsal de guerra español}

El primer conflicto en el que medios de comunicación tradicional recogieron testimonios de internautas, fue durante el conflicto de Kosovo de 1999 en el que los albaneses relataban a través de sus blogs, las violaciones de los derechos humanos que sufrían por parte de las autoridades serbias. Más tarde, en 2011, los blogueros brindan dramáticos testimonios sobre el atentado del 11 de septiembre a las Torres Gemelas en Nueva York. Pero no fue sino hasta la guerra de Irak de 2003 en la que la blogosfera se convierte en una fuente complementaria y crítica frente a los medios convencionales, superando incluso en inmediatez a las cadenas de radio y televisión (Carreras \& Román, 2011). Los blogueros y sus blogs empiezan a considerarse como una alternativa al periodismo tradicional y se puede considerar que tienen su culmen -al menos por el momento- en los nanoblogs ubicados en las entrañas de las redes sociales como Twitter, que ha demostrado un gran poder comunicativo y a la vez, ser fuente inagotable de información para el periodismo tradicional que ha iniciado también sus andaduras en esos espacios. Esta condición de

ICONO14 | Año 2015 Volumen 13 Nº 2 | ISSN: 1697-8293 | DOI: ri14.v13i2.783 
inmediatez y cercanía que son característicos de los medios nacidos bajo el ala de Internet, ha hecho que los medios de comunicación demanden de sus periodistas el uso de estas herramientas en zonas de conflicto. Antonio Pampliega, corresponsal freelance, explica que les permite llegar a más gente en menos tiempo pero que:

Las redes sociales son un mal escaparate para los demás. Si el corresponsal cuelga sus trabajos o sus fotos mientras trabaja eso puede llevar a confusión al receptor del mensaje y que puede llegar a pensar que cualquiera puede cubrir una guerra y que es muy sencillo llegar hasta donde hemos llegado (Pampliega, 2013).

De hecho, son muchos los corresponsales que utilizan esta herramienta para publicitar sus textos como Alfonso Armada que afirma que muchos lectores les llegan por esta vía (2013) o Mónica G. Prieto que apunta que muchos usuarios, "no se informan a través de medios convencionales sino exclusivamente por Internet siguiendo las recomendaciones que le hacen sus amigos por Facebook y Twitter y ahí te salen más visitas que los que pueden visitar tu página web" (G. Prieto, 2013).

Pero Javier Espinosa considera que una cosa es utilizarlo para publicar textos y otra para informar, marcando así la diferencia entre lo que es comunicación de lo que es periodismo,

Yo no considero Twitter o Facebook, periodismo, sino un medio de comunicación, con lo cual, que tu retuitees o mandes cosas por Facebook no quiere decir que estés haciendo periodismo. (...) Tú puedes hacer un gran reporterismo sin tener que comunicarte por Twitter o Facebook, aunque yo lo hago (Espinosa, 2013).

Durante las revueltas en Egipto del 2011, los blogs y las redes sociales, se convirtieron en plataforma de información no sólo de difusión, relatando los acontecimientos de los que han sido testigos los propios egipcios, sino también a través de vídeos e imágenes que han colgado en la red, poniéndolos a disposición de todos los internautas (Carreras \& Román, 2011). 
A todo esto, se le ha denominado periodismo ciudadano, habitantes de la zona de conflicto que con una cámara digital graban sin criterios profesionales, en muchos casos, imágenes y sonidos que luego emiten los medios de comunicación (Salvat y Paniagua, 2007). Internet ha roto el modelo comercial del viejo periódico, moviendo información a coste cero, lo que significa que ésta no tiene barreras que superar, al contrario que el periódico, que tiene que pagar por el papel, la tinta y el transporte. Alfonso Rojo explica que el gran efecto de Internet, es que permite a cualquiera con un ordenador y una conexión a Internet poner en circulación información: "antes los periodistas éramos intermediarios imprescindibles, éramos los únicos que teníamos el acceso a las fuentes, los únicos que en teoría teníamos la técnica para contarlo y los únicos que teníamos los canales para contarlo" (Rojo, 2013).

Pero los corresponsales ponen en cuarentena este tipo de 'periodismo', Alfonso Armada afirma:

Yo sería muy cauteloso en esta especie de fascinación por el periodismo ciudadano. No todo el mundo que escribe ni que sube una imagen es periodista. No soy nada gremial pero hay una serie de requisitos, una cosa es información y otra cosa es comunicación o propaganda. Y esos requisitos mucha gente no los cumplen, muchas veces es opinión, cuentan los que han visto, pero puede ser muy útil para acercarse a la verdad, pero no se puede definir eso como información (Armada, 2013).

0 como también plantea Ángeles Espinosa “la información es cara y requiere dedicar un tiempo que dificilmente alguien con otro trabajo de 8 horas y una vida normal puede realizar salvo que sea militante de una causa o tenga otros intereses" (2013). Algo que apoyan investigadores como Real (2007) que afirman que cualquier ser humano puede ser comunicador social, pero que lo que hace no se puede considerar periodismo.

Muchos ven en este tipo de información un posible interés oculto, que sólo los periodistas van a poder contrastar y confirmar como información, Enric González pone un ejemplo: “en la guerra de Siria, tiene poco valor hasta que llega un perio- 
dista que confirma o desconfirma lo que se ofrece en YouTube y Twitter. Todo es material en bruto que en sí no vale gran cosa" (González, 2014) o Alfonso Bauluz que considera que los activistas son actores que intoxican y apunta "Lo que hay además de falta de rigor profesional, es el interés en depreciar el trabajo de los periodistas de verdad, a las empresas le ha venido muy bien" (Bauluz, 2013). Y va más lejos incluso, asegurando que los corresponsales se han convertido en objetivos en los conflictos porque son testigos incómodos. Afirmando que en los conflictos, los periodistas occidentales ya no son necesarios porque cualquiera pueda mandar un vídeo a una cadena y obtienen gran repercusión como los vídeos de los insurgentes en Irak: "aparecen en todos los medios de comunicación de todo el mundo, sin que un solo periodista haya tocado ese material y lo haya verificado" (Bauluz, 2013).

Hay otros corresponsales como Rosa María Calaf, excorresponsal de TVE, que son menos críticos con este tipo de "información":

En principio todo lo que es información es bueno. Cuanta más gente pueda opinar, mejor. Pero debe dejarse claro antes. Puede haber recursos de un ciudadano de la calle útiles: una foto de móvil, por ejemplo. Pero debe hacer límites porque esto es una responsabilidad. Debería haber más filtros. No estoy en contra del periodismo ciudadano porque creo que hay que explicar muy bien a la gente que eso no quiere decir que sea sinónimo de creíble. Uno mismo debe hacer una comprobación (...). Eso también es una obligación de los medios de comunicación, explicarlo a los ciudadanos. Que miren con cuidado los datos que aparecen (Calaf, 2008, pág. 110).

0 como Mónica G. Prieto que apunta: “Twitter ha dado la posibilidad de que haya un volumen de información que antes no se hubiera podido dar de Oriente Próximo. Yo me he enterado de temas por Twitter porque no salen en prensa tradicional" (G. Prieto, 2013).

Así, el contraste entre los medios surgidos a partir de Internet, el trabajo del periodista y las demandas de los propios medios de comunicación ha generado una forma de exposición, difusión y consumo de los medios que son, sin duda, efectos que han condicionado a la profesión periodística.

DOI: ri14.v13i2.783 | ISSN: 1697-8293 | Año 2015 Volumen 13 N² 2 | ICONO14 
Otro de los efectos de estos medios virtuales es que las primicias periodísticas cada vez duran menos, lo que obliga a estos profesionales a extremar sus esfuerzos, muchas veces aumentando los riesgo de obtención de información para seguir teniendo presencia en un mercado cada vez más competitivo (Pizarroso Quintero, González San Ruperto, \& Sapag Muñoz de la Peña, 2007). Esto lo explica Mónica G. Prieto, cuando considera que las redes sociales se pueden volver en contra del corresponsal: "hay que tener mucho cuidado, sobre todo porque puedes matar historias en las que están trabajando si estás tuiteando todo. Te obliga a estar muy pendiente y a trabajar el triple" (G. Prieto, 2013).

Tomás Alcoverro subraya esta posición de Prieto, pero desde una óptica más bien negativa de la situación en la que se encuentran los corresponsales en la actualidad debido a esta multiplicidad de emisores: "En una época se hablaba del corresponsal como una excelencia, pero esto se ha acabado, ahora es una voz más, que además hace todo a la vez, vídeos, artículos, Twitter. Esto ha perjudicado un trabajo que ya no es artesano" (Alcoverro, 2013).

Guillermo Altares, corresponsal y actualmente, redactor jefe de la sección Internacional de El País, valora las nuevas posibilidades que da este medio periodísticamente cuando apunta que "en el golpe de estado de El Cairo, todos los grandes periódicos del mundo, tenían un directo, no de imagen, sino de texto" (Altares, 2013).

La actualización de la información fue vía los Twitter, medio que a la vez, permitió colgar imágenes de modo inmediato. La evolución tecnológica ha provocado una transición en el espectador, a una velocidad de consumo que ha obligado a los medios tradicionales a adaptarse al nuevo paradigma (Tognazzi, 2012).

A la vez, un sector que se ha resentido especialmente es el de los profesionales de la imagen. Se trata de un debate a varias voces en los que unos consideran que a los medios no les importa bajar la calidad de sus emisiones con tal de usarlas gratuitamente, como afirma Javier Espinoza (2013), o que respaldan la profesionalidad y la formación para cubrir los eventos noticiosos, como apunta Mónica G. Prieto (2013), o como señala Gervasio Sánchez (2013) que Internet se ha conver- 
tido en un espacio para que se pirateen las imágenes capturadas por los fotógrafos sin pagar por ellas.

En ese sentido, diversas voces hablan sobre la fotografía y la evolución tecnológica asociada a ella. Lister (2011) afirma que los problemas se han agravado en vez de haberse resuelto dando lugar a una edad oscura digital. Otros como Marinello (1996), Campany (2007) o Corral (2012), son más optimistas considerando que se ha visto revitalizada por la participación de millones de nuevos actores y que abrirá nuevos caminos y estéticas. Campbell (2010) además valora que estos nuevos medios permitan que la audiencia de sus historias crezca y que los que anuncian el fin del fotoperiodismo se refieren al ocaso de los sistemas de distribución tradicional .

Mónica G. Prieto, es quizá una de las más optimistas frente a los medios virtuales. Valora positivamente a la red por el espacio indefinido que les da "en televisión tienes 50 segundos o en el periódico 3.500 caracteres, (...) en la web puedes escribir lo que quieras (...) Internet te permite publicar 10 fotos en vez de $1 \mathrm{y}$ todo el texto que quieres" (G. Prieto, 2013).

Siguiendo esta línea de espacio indefinido, los medios también se están adaptando a estas nuevas plataformas y la prensa escrita, radio, televisión y agencias de comunicación, ya que difunden información a través de las redes sociales, con el fin de llegar más fácilmente a sus lectores y conseguir mayores cuotas de audiencia, además de intentar fomentar la interactuación con los usuarios. También se han convertido en el eje fundamental a través del que se estructuran los nuevos proyectos de crecimiento y expansión. Con Twitter intentan ganar en inmediatez, ser los primeros en dar la noticia e ir actualizando a medida que se tienen más datos, además de incluir los vínculos que lleve a los lectores a la noticia del medio. De esa forma, la prensa digital, al incluir vídeos, podscasts y señales en directo, compite en inmediatez con la propia televisión.

El fotógrafo Benjamin Lowy, reconocido por retratar conflictos con la cámara de su móvil, se encargó de cubrir en directo la llegada del huracán Sandy para la revista Time. Su trabajo consistió en subir imágenes de los efectos del huracán a la cuenta de Instagram de la revista, generando así un 13\% más de visitas a la web y

DOI: ri14.v13i2.783 | ISSN: 1697-8293 | Año 2015 Volumen 13 N² 2 | ICONO14 
atrayendo a 12.000 nuevos seguidores. Además una de sus instantáneas fue portada de la revista en papel (Bercovici, 2012).

\subsection{Otros efectos}

\subsubsection{Información constante}

Muchos de los corresponsales han incidido sobre un cambio que se está produciendo por el hecho de que la transmisión sea inmediata y dispongan de dispositivos móviles, algo que según Alfonso Armada se está agravado en la actualidad:

La obsesión ahora es tener constantemente material, vía Twitter, actualizar un blog o Twitter, mandar crónicas sucesivas a lo largo del día. Creo que eso ha envilecido bastante el producto y la vida de los corresponsales, creo que ahora se ha deteriorado bastante. Esa especie de ansiedad, la web está siempre abierta, y esa especie de obsesión por actualizar permanentemente ha degradado el trabajo (Armada, 2013).

En contraste con esta llamada de atención de Armada, la inmediatez que imponía el consumo de la prensa del siglo XIX -aún antes de la existencia del cable submarino transatlántico y de la radio- implicaba que los periodistas se desplazaran en botes de remo al encuentro de los barcos que llegaban al puerto de Nueva York para tener noticias de Europa lo más rápido posible. La prensa de entonces necesitaba que sus reporteros tuvieran sus informaciones antes del cierre de la rotativa para que el periódico estuviera en los quioscos a primera hora de la mañana. Como consecuencia de ese imperativo tecnológico, los periódicos y otros medios informativos han hecho el cumplir con el cierre de la edición una obsesión (Pavlik, 2005).

Este frenesí por la inmediatez, porque la prensa tenga las noticias más frescas a primera hora de la mañana se ha agudizado con la aparición de la prensa digital, tal y como constata Ángeles Espinosa, corresponsal del periódico El País, aunque Internet simplifica las tareas también les genera un enorme estrés porque les obliga "alimentar continuamente la rueda informativa que redunda en una menor reflexión y falta de tiempo para elaborar los trabajos" (Espinosa, 2013). Y apunta

ICONO14 | Año 2015 Volumen 13 Nº 2 | ISSN: 1697-8293 | DOI: ri14.v13i2.783 
que el tiempo que se gana no se dedica a profundizar en el trabajo sino a enviar más textos y pone un ejemplo revelador de esta circunstancia:

En mi primer viaje al Kurdistán iraquí, en 1991, pasé tres días perdida en las montañas antes de regresar a Bagdad y elaborar un reportaje sobre la situación allí. En 2004, tras la invasión estadounidense, a menudo viajaba de Bagdad a Erbil para cubrir un atentado y volvía en el mismo día... Ahora hay que escribir una primera crónica desde por la mañana o cuando se produce el evento para colgarla corriendo en la web, rehacerla para la edición en papel y además mantener un blog y estar a la última en Twitter (Espinosa, 2013).

Enric González apoya esta visión dual que ayuda a la hora de trabajar pero que "fomenta el ansia de las redacciones de tener de todo y ya, tener información constante, renovar las ediciones digitales y en ese sentido empeora" (González, 2014).

El excorresponsal de Antena 3, Javier Mellado también confirma que en televisión también se deteriora su trabajo si está apareciendo continuamente y señala que necesita tiempo para hacer un buen trabajo en terrenos que no son fáciles: "no es que esté las 24 horas escribiendo, grabando o viendo, pero si pensando, hablando con gente, viendo por dónde sí o por dónde no" (Mellado, 2012).

Este ritmo constante, según Alfonso Armada, "crea una ansiedad permanente y de confusión, es un círculo vicioso, no informa, entretiene y te crea adicción" (Armada, 2013). Además, la creación de diarios digitales y las redes sociales ha provocado que las noticias se queden desactualizadas prácticamente al poco de publicarse.

\subsubsection{Fugacidad de la noticia}

La vida de las noticias se ha hecho más corta, como explica Alfonso Bauluz, el ciclo informativo se ha modificado con la inmediatez en la transmisión "si antes era de 24 horas, ahora es de 24 minutos. Eso significa que la información que se consume, se muere antes. Hay más demanda y la información es más perecedera, por lo que hay que enviar más. La tecnología te permite hacerlo. ¿Qué sea mejor? No necesariamente" (Bauluz, 2013).

DOI: ri14.v13i2.783 | ISSN: 1697-8293 | Año 2015 Volumen 13 N² 2 | ICONO14 
Guillermo Altares (2013) tiene claro que este es uno de los cambios que ha producido una alteración en el paradigma informativo, porque la gente quiere consumir información en el mismo momento en que ocurren los acontecimientos.

Otro de los efectos de esta fugacidad es que hace que la noticia pierda interés en pocas horas, porque se queda desactualizada o aparecen otras informaciones que la sustituye, por lo que crónicas de corresponsales, que les ha podido costar bastante tiempo y esfuerzo, son eliminadas a las pocas horas y sustituidas por otras noticias, tal y como referenció Mónica G. Prieto (2013).

Por su parte, Javier Mellado que no se pueden hacer reportajes con el cuidado que se hacían porque si trabajar para televisión "tienes que salir aunque no digas nada. No interesa la profundidad de la información, sino que estás ahí que es lo que vende. Prima el espectáculo" (Mellado, 2012).

Enric González considera que hay dos tipos de información, pero que indudablemente se ha producido un cambio:

Una cosa es la noticia que se queda vieja en horas o en minutos y luego están las historias, las piezas que son de lectura. Si la noticia es que se ha muerto alguien, quién lo dice primero, vale, lo ha dicho primero pero lo importante es contar bien quién era y lo que ha rodeado su vida, cosas que no son inmediatas y que tienes que trabajar, esa es la diferencia. La noticia realmente se ha devaluado, antes valía que tú consiguieras una noticia, ahora vale menos. Ahora lo que importa es que tengas todo lo que rodea la noticia, es decir, la información y para conseguirlo necesitas trabajar como se ha hecho siempre (González, 2014).

En otras ocasiones, se dejan de actualizar temas si consideran que no interesan, algo sobre lo que reflexiona la antigua corresponsal de TVE, Rosa María Calaf "cada vez los temas se acaban más deprisa. Empezamos a hablar de un tema y desaparecen. Sin embargo, eso no quiero decir que el problema haya desaparecido" (Calaf, 2008, pág. 105).

ICONO14 | Año 2015 Volumen 13 Nº 2 | ISSN: 1697-8293 | DOI: ri14.v13i2.783 
Según los corresponsales, esta posibilidad de informar en cualquier momento y de forma constante ha generado coberturas superficiales, en las que no hay tiempo ni interés por parte de algunos medios de profundizar en la información.

\subsubsection{Inmediatez a la hora de informar}

El tema de la inmediatez informativa ha primado desde siempre, aunque los condicionantes de velocidad han estado vinculados, como se apuntaba, a los recursos técnicos de cada época, como los botes de remos o Twitter. Lo que no se debe confundir es la rapidez o inmediatez informativa con calidad periodística (Bauluz, 2013), aunque voces de las entrevistadas consideran que a los medios de comunicación poco les importa la calidad informativa frente a la posibilidad de dar la primicia, asumiendo que el público tiene razón cuando piensa "que rapidez es sinónimo de calidad y es mentira" (Pampliega, 2013).

Esta falta de calidad, también la evidencia Enric González, y critica esta velocidad mal entendida por los medios:

Empezamos a salir de la idiotez de la rapidez, es decir, ya que puedes hacerlo rápido, hazlo rápido, haces tuits, te conectas con no sé quién y vas dando pildoritas...eso es una tontería. El periodismo tiene varias velocidades, y el que me interesa a mí, es el periodismo lento, el de ciclo semanal o mensual, el otro está al alcance de todo el mundo, es gratis y lo tienes de forma inmediata, pero no vale la pena preocuparse por eso. Ya hay gente que cobra por hacer eso o incluso que no cobra nada y lo hace. Se trata de hacer un producto para la gente más elaborado, que es lo que puede leer alguien, lo otro no se lee, se ve (González, 2014).

Javier Espinosa también es de la misma opinión: “a mí como lector me gusta leer un reportaje que me explique lo que ha pasado (...), me gusta el reportaje más pausado. En The Guardian hay reporteros que le dan dos meses para escribir un artículo y eso no tiene comparación con el impacto de un tuit" (Espinosa, 2013). Alfonso Rojo, también percibe un cambio en la información de conflictos, pero la compara con la cobertura deportiva, considera que esta obsesión por dar las infor-

DOI: ri14.v13i2.783 | ISSN: 1697-8293 | Año 2015 Volumen 13 N² 2 | ICONO14 
maciones el primero, provoca que las informaciones se queden con lo superficial y no se profundice, igual que la retransmisión de un partido de fútbol en la que sólo se narra lo que se ve. En general, la mayoría de los corresponsales consideran, como Ángeles Espinosa, que ahora "no vale hacer una buena historia sino que hay que hacerla lo antes posible" (2013). Otros como Fran Sevilla ven la inmediatez como "el aspecto positivo, y las prisas y la urgencia el aspecto negativo" (Sevilla, 2013). Y Mónica G. Prieto zanja de forma clara el debate: "No hay que darlo el primero, hay que darlo bien, sabiendo que lo que estás dando es cierto" (G. Prieto, 2013).

Pero, el corresponsal Alfonso Armada, no sólo va en la misma línea sino que advierte un cambio en la información, que la obsesión por la rapidez ha hecho que se vuelva más espectacular:

Las redacciones se están empequeñeciendo, muchas redacciones no tiene ya ni correctores, creo que ahí está fallando, se difunden un montón de informaciones que no tienen ni pies ni cabeza, que están cogidas con una sola fuente y ese es el peligro de la inmediatez. A veces se difunden cosas que hubiera sido mejor guardar. A mí por eso me gusta la información mucho más lenta. Esta obsesión por publicar cuando muchas veces no son noticia (Armada, 2013).

\subsubsection{Credibilidad}

Esta rapidez por ser el primero en contarlo hace que muchas veces se comentan errores, porque no se contraste una información o porque se emitan unas imágenes erróneas, lo que provoca, a la larga, el no poder reposar la información, es una pérdida de credibilidad. Ángeles Espinosa considera que eso pasa "si nos dejamos obnubilar por la tecnología y no separamos oportunamente el trigo de la paja" (Espinosa, 2013).

Vicente Romero, corresponsal de TVE, nos hace reflexionar sobre este cambio, apuntando a otro efecto:

Las imágenes se veían 24, 48 horas o tres días después porque había que revelar la película, montarla. Ahora hay una inmediatez en la información enorme. 
Hace años que nos están diciendo que el gran desafío es la inmediatez, la rapidez, pero ahora más que nunca, el gran desafío es la ética. La forma de contar las cosas, lo que hay que contar, lo que hay que callar, el saber a quién sirve o perjudica las noticias que distribuyes, no caer en trampas, etc. La inmediatez hace que las noticias salgan fuera de contexto, se atropellen, se solapen unas a otras y que la manipulación informativa sea más fácil de hacer que hace unos años (Romero, 2014).

Javier Espinosa está de acuerdo con que se han cometido muchos errores y en parte por la mala praxis de los propios periodistas y argumenta:

Se cuelan muchos gazapos, mentiras. Hay una pérdida de credibilidad general en el periodismo, pero también por nuestras propias prácticas, pero la democratización del periodismo ha hecho que también haya muchas informaciones que no son veraces y entonces la gente empieza ya a dudar en general. Eso tiene un riesgo, por eso hay que diferenciar entre redes sociales y los medios de comunicación que si se les debería exigir un rigor. Los medios de comunicación intentan aproximarse a las redes sociales en vez de diferenciarse. Los periódicos en vez de dar artículos más largos, más pausados, más reportajes, lo que han hecho es reducir los artículos, ahora el espacio es menor a cuando yo empecé en El Mundo. Han pasado de 7.000 caracteres a 5.000 por lógica la información que te cabe es menor y con juegos de más fotos, intentan acercarse a Internet. Pero Internet ya está y además es gratis. Los medios que están funcionando a nivel de pago, son los medios que se alejan de Internet (Espinosa, 2013).

A pesar de las posibilidades que proporciona Internet para la recogida de datos, no es la panacea para los periodistas. Gran parte de los contenidos que pueden verse en la red son de origen dudoso, e incluso deliberadamente engañosos.

\subsubsection{Acceso a fuentes}

La aparición de Internet y su uso cada vez más generalizado ha supuesto importantes novedades tanto a la hora de cubrir un conflicto armado como la de obtener información sobre el mismo a nivel de usuario. Esto permite a los corresponsales

DOI: ri14.v13i2.783 | ISSN: 1697-8293 | Año 2015 Volumen 13 N² 2 | ICONO14 
de guerra trabajar de una forma más eficaz y eficiente cuando se encuentre en lugares lejanos o desconocidos, pueden verificar datos sobre el terreno. También les ayuda a la hora de localizar posibles artículos y fuentes. Tienen acceso instantáneo a inmensas bases de datos a las que antes sólo podía acceder examinándolas in situ (Pavlik, 2005). Alfonso Bauluz explica esta facilidad para acceder a nuevas fuentes: "Desde que tienes acceso a distintos actores del frente o expertos que te permite contrastar, la verdad es que eso facilita mucho" (Bauluz, 2013). Ángeles Espinosa sobre todo valora el hecho de poder acceder a documentación o seguimiento de noticias en los medios internacionales pero que también "ayuda a encontrar a fuentes e incluso a concertar entrevistas" y remarca "es un instrumento muy útil, pero en ningún caso suple la presencia en directo del corresponsal sobre el terreno" (Espinosa, 2013).

Es importante este apunte, ya que muchos medios han aprovechado estas nuevas fuentes para informar de algún conflicto como explica Ángeles Espinosa "el peligro es considerar que se puede acceder a la información de primera mano y los testimonios sin necesidad de trasladarse a los lugares donde se producen las noticias. A este respecto, lo que ha afectado es la crisis económica y la falta de recursos. Internet se convierte en la excusa perfecta para no viajar, pero lo que impide hacer la cobertura es no disponer de presupuesto" (Espinosa, 2013). Por ello Vicente Romero recuerda "cometes una cantidad de errores enormes porque las fuentes no están contrastadas" (Romero, 2014). Alfonso Armada tiene claro el valor de las fuentes a través de las redes sociales:

En Facebook y en Twitter tienes muchas fuentes y puedes componer una historia, pero al final estás recurriendo a fuentes. Es una ayuda pero es mejor ir allí, mejor ver y tocar y estar en el lugar de los hechos. Es una herramienta más, el problema es cuando eso sustituye a la mirada personal (...). Es verdad que a través de estas redes puedes acceder pero a veces te falta comprobar quién habla porque propicia crear nuevas máscaras. A veces es difícil saber quién hay detrás, tienes menos elementos de juicio para saber si te están engañando o no (Armada, 2013).

Enric González afirma que este acceso les permite ahorrar tiempo al poder acceder a una base de datos digitalizada "hace que no tengas que estar dos horas

ICONO14 | Año 2015 Volumen 13 N² | ISSN: 1697-8293 | DOI: ri14.v13i2.783 
buscando el nombre de pila de un ministro pero por otro lado lo empeora porque se exigen más envíos, más inmediatez y se superficializa todo" (González, 2014). También considera que las redes sociales permiten localizar a fuentes con mayor facilidad "El acceso a fuentes normales, no hablamos de periodismo de investigación, de periodismo normal, pues sí, es todo bastante más fácil y más rápido" (González, 2014).

\section{Conclusiones}

Es innegable que Internet y las redes sociales han afectado al trabajo de los corresponsales de guerra, aunque no es unánime la opinión sobre el efecto en su trabajo, algunos ven que estos nuevos medios les han abierto puertas y les ha facilitado su quehacer, mientras que otros son mucho más escépticos. Pero en lo que sí que hay unanimidad es en reclamar que más que nunca, el trabajo de los corresponsales es fundamental en actualidad. En Internet y en las redes sociales aparecen informaciones e imágenes sin contrastar y sólo ellos, periodistas profesionales especializados, son capaces de verificar y arrojar luz sobre lo que realmente está pasado en un conflicto donde por lo general todo es muy confuso. Saben lo que es enfrentarse a grandes campañas de propaganda y manipulación de los países implicados y su figura es esencial para no acrecentarla sensación de falta de credibilidad en el consumidor de información.

Pero también, las redes sociales les han convertido, como ellos dicen, en "multimedia" y realizan nuevas tareas, se les pide que además de hacer su trabajo habitual, participen de las redes sociales o si su empresa pertenece a un grupo de comunicación, se le solicita que trabaje además para el resto de medios. El hecho de tenerles en comunicación constante hace que se pierdan muchas veces lo que esté pasando.

Las nuevas herramientas que han permitido a los corresponsales transmitir en directo desde cualquier sitio y en cualquier momento, han acarreado que desde las redacciones se le solicite al corresponsal información constantemente. Se necesita información nueva para que el lector o el telespectador siga consumiendo, lo que ha provocado que los corresponsales de conflictos, participen más veces de lo que había sido habitual hasta entonces.

DOI: ri14.v13i2.783 | ISSN: 1697-8293 | Año 2015 Volumen 13 N² 2 | ICONO14 
Otra premisa que se ha agudizado con esta información constante es que todos los medios rivalizan en ser los primeros en dar una noticia, novedades sobre el conflicto, el número de muertos, etc. Un concepto que se ha intensificado en la actualidad, provocando un mayor estrés a los corresponsales.

Toda esta información constante y la guerra por dar las primicias sobre los conflictos ha generado que el ciclo informativo acorte su duración, las noticias de un corresponsal pueden llegar a quedarse desactualizada en minutos, devaluándose así su valor. Son muchos los corresponsales que se lamentan que sus crónicas a veces sólo se mantengan horas en las ediciones digitales. El trabajo que tanto tiempo ha tardado en elaborar, arriesgando en ocasiones su vida, puede ser relegada por el último teletipo de una agencia o una información aparecida en las redes sociales.

Además, toda esta carrera ha originado que los corresponsales cuenten con menor tiempo para reposar la información, analizarla o incluso contrastarla, lo que en palabras de los corresponsales, ha producido coberturas superficiales y por tanto una carencia de calidad. $\mathrm{E}$ indirectamente, un pérdida de credibilidad, aunque consideran los corresponsales que es más una percepción provocada por la información en general y no tanto por la de conflictos, aunque también recuerdan importantes errores en la cobertura de algunas de las ultimas guerras, pero sin dirigirla hacia su trabajo.

Pero es indudable que también Internet y las redes sociales les han ayudado a tener un acceso más rápido a las fuentes o para documentarse sobre el país al que van a viajar, pero también ayuda a la hora de contrastar las informaciones.

\section{Referencias}

Alcoverro, T. (Entrevista personal, 3 de octubre de 2013).

Altares, G. (Entrevista personal, 4 de julio de 2013).

Armada, A. (Entrevista personal, 9 de octubre de 2013).

Bauluz, A. (Entrevista personal, 17 de junio de 2013).

Bercovici, J. (11 de 1 de 2012). Why Time Magazine Used Instagram To Cover Hurricane Sandy. Obtenido de http://www.forbes.com/sites/jeffbercovici/2012/11/01/ 
why-time-magazine-used-instagram-to-cover-hurricane-sandy/

Bowman, S., \& Willis, C. (2003). Nosotros, el medio. Colombia: Casa Editorial El Tiempo.

Braojos Garrido, A., García González, G., De Pablo Contreras, S., Paz Rebollo, M. A., \& Scuzle Schneider, I. (1999). Historia del periodismo universal. Madrid: Síntesis.

Calaf, R. M. (2008). El diseño de la información internacional. En M. J. Martín, \& M. C. (Editores), La arquitectura de la información. ¿Quién construye la agenda? (págs. 97-113). Murcia: DM.

Carreras, M. d., \& Román, A. (2011). Redes sociales y herramientas 2.0 en la revuelta de Egipto. El poder de derribar un regimen. En X. C. Digital, La investigación en periodismo digital. Algunos trabajos desde el ámbito universitario (pp. 336349). Zaragoza: Asociación de Periodistas de Aragón.

Corral, P. (2012). La fotografía como lenguaje. Cuadernos de periodistas, 67-79.

Campany, D. (2007). Seguridad en la parálisis: algunas observaciones sobre los problemas de la "fotografía tardía". En D. Green, ¿Qué ha sido de la fotografía? (pp. 135-146). Barcelona: Gustavo Gili.

Campbell, D. (2010). Photojournalism in the New Media Economy. Nieman Report , $15-17$.

Espinosa, Á. (Entrevista personal, 25 de noviembre de 2013).

Espinosa, J. (Entrevista personal, 15 de julio de 2013).

Gillmor, D. (2004). We the Media. Sebastopol: 0'Reilly Media.

González, E. (Entrevista personal, 16 de enero de 2014).

Knightley, P. (2000). The First Casualty. The war correspondent as hero and mythmaker from the Crimea to Kosovo.London: Prion Books.

Lavín, E. (2014). El periodismo ciudadano: una herramienta para las televisiones americanas (pp. 77-90). En Gallardo, J.y Vadillo, N. (coordinadores), Las nuevas tecnologías audiovisuales frente a los procesos tradicionales de comunicación. La Laguna (Tenerife): Sociedad Latina de Comunicación Social.

Lister, M. (2011). ¿Demasiadas fotografías? La fotografía como contenido generado por el usuario. adComunica. Revista Científica de Estrategias, Tendencias e Innovación en Comunicación , 25-41.

Marinello, J. D. (1996). La apuesta de Gates. Cuadernos de información, 68-71. Mellado, J. (Entrevista personal, 13 de junio de 2012). 
Pampliega, A. (Entrevista personal, 4 de enero de 2013).

Pavlik, J. V. (2005). El periodismo y los nuevos medios de comunicación. Barcelona: Paidós Ibérica.

Pizarroso Quintero, A., González San Ruperto, M., \& Sapag Muñoz de la Peña, P. (2007). Periodismo de guerra. Madrid: Síntesis.

Prieto, M. G. (Entrevista personal, 20 de octubre de 2013).

Real Rodríguez, E., Príncipe Hermoso, S., \& Agudiez Calvo, P. (2007). Periodismo ciudadano versus Periodismo profesional: ¿somos todos periodistas? Estudios sobre el Mensaje Periodístico, 189 - 212.

Rojo, A. (Entrevista personal, 5 de octubre de 2013).

Romero, V. (Entrevista personal, 21 de enero de 2014).

Salvat, G. y Paniagua, P. (2007). “¿Es esto periodismo, ciudadano?”. Estudios sobre el Mensaje Periodístico, pp. 227-246.

Sánchez, G. (Entrevista personal, 4 de febrero de 2013).

Sevilla, F. (Entrevista personal, 2 de julio de 2013).

Strauss, A., \& Corbin, J. (2002). Bases de la investigación cualitativa. Técnicas y procedimientos para desarrollar la teoría fundamentada. Medellín: Universidad de Antioquia.

Tognazzi Drake, A. (2012). Las transformaciones de los contenidos audiovisuales y la influencia de los dispositivos móviles en el nuevo escenario transmedia. Anàlisi: quaderns de comunicació i cultura, pp. 81-95 